\title{
Influence of continental roots and asthenosphere on plate-mantle coupling
}

\author{
Clinton P. Conrad ${ }^{1}$ and Carolina Lithgow-Bertelloni ${ }^{2}$ \\ Received 26 December 2005; revised 25 January 2006; accepted 31 January 2006; published 15 March 2006.
}

[1] The shear tractions that mantle flow exerts on the base of Earth's lithosphere contribute to plate-driving forces and lithospheric stresses. We investigate the sensitivity of these tractions to sub-lithospheric viscosity variations by comparing shear tractions computed from a mantle flow model featuring laterally-varying lithosphere and asthenosphere viscosity with those from a model with layered viscosity. Lateral viscosity variations generally do not change the direction of shear tractions, but deeply penetrating continental roots increase traction magnitudes by a factor of $2-5$ compared to $100 \mathrm{~km}$ thick lithosphere. A low-viscosity asthenosphere decreases traction magnitudes by a smaller amount, and is important only if $>100 \mathrm{~km}$ thick. Increased plate-mantle coupling beneath thick continental lithosphere may increase plate-driving forces, surface deformation, and mantle-derived lithospheric stresses in these regions. By contrast, a low-viscosity asthenosphere does not decouple the lithosphere from mantle flow, highlighting the geological importance of mantle tractions on the lithosphere. Citation: Conrad, C. P., and C. Lithgow-Bertelloni (2006), Influence of continental roots and asthenosphere on plate-mantle coupling, Geophys. Res. Lett., 33, L05312, doi:10.1029/2005GL025621.

\section{Introduction}

[2] Viscous flow in the mantle exerts shear tractions on the base of the Earth's rigid lithosphere [e.g., Hager and O'Connell, 1981]. These shear tractions contribute to the crustal deformation and tectonic plate motions that we observe at the Earth's surface, but their influence depends on how mantle flow couples to the plates. There are two rheological controls that are thought to exert a primary influence on this coupling. First, several observations [e.g., Hager, 1991] suggest that the lithosphere is underlain by a low-viscosity asthenospheric layer that may be related to observed zones of low seismic velocity $\sim 100-300 \mathrm{~km}$ beneath oceanic and tectonically active regions, and possibly beneath continents [Gung et al., 2003]. This lowviscosity asthenospheric layer may partially decouple the plates from mantle flow [e.g., Forsyth and Uyeda, 1975]. Second, the thickness of the lithosphere may vary significantly across tectonic regimes (Figure 1). Oceanic lithosphere thickens as it cools, which causes the "roof" of the low-viscosity asthenosphere to descend away from ridges

\footnotetext{
${ }^{1}$ Department of Earth and Planetary Sciences, Johns Hopkins University, Baltimore, Maryland, USA.

${ }^{2}$ Department of Geological Sciences, University of Michigan, Ann Arbor, Michigan, USA.
}

Copyright 2006 by the American Geophysical Union. 0094-8276/06/2005GL025621 [e.g., Hirth and Kohlstedt, 1996]. Continental lithosphere may feature even larger variations in thickness, including continental "roots" that may penetrate to depths of up to $\sim 400 \mathrm{~km}$ beneath cratonic shields [e.g., Jordan, 1975; Ritsema et al., 2004], and are likely cold and highly viscous [e.g., Rudnick et al., 1998]. These deeply-penetrating continental roots may couple to mantle flow more effectively than thinner lithosphere [e.g., Stoddard and Abbott, 1996; Zhong, 2001].

[3] Models of mantle flow have been used to calculate shear tractions on the base of the lithosphere in studies that predict the lithospheric stress field [e.g., Steinberger et al., 2001; Lithgow-Bertelloni and Guynn, 2004] and global plate motions [e.g., Lithgow-Bertelloni and Richards, 1995; Becker and O'Connell, 2001; Conrad and LithgowBertelloni, 2002]. These studies assume a lithospheric layer with uniform viscosity and thickness. Other studies that do introduce a lithosphere of varying thickness [e.g., Stoddard and Abbott, 1996; Zhong, 2001; Çadek and Fleitout, 2003] do not examine the shear tractions on plates directly. In this study, we quantify how lateral variations in lithospheric thickness and the presence of an asthenosphere affect the shear tractions that the mantle exerts on the base of plates. These results will be directly applicable to our understanding of how mantle flow drives crustal deformation and plate motions.

\section{Mantle Tractions on the Lithosphere}

[4] To introduce lateral variations in lithospheric and asthenospheric viscosity into a numerical model of mantle flow, we use the spherical finite element code CitComS, which has been benchmarked extensively and can handle orders of magnitude variations in viscosity [Zhong et al., 2000]. We set up a global finite element grid with 874800 elements, including 24300 surface elements corresponding to $157 \mathrm{~km}$ horizontal resolution at the surface. Vertical resolution is $150 \mathrm{~km}$ in the lower mantle, $50 \mathrm{~km}$ in the upper mantle, and $25 \mathrm{~km}$ above $350 \mathrm{~km}$ to better resolve shear tractions. We calculate instantaneous Stokes flow in the mantle using a density heterogeneity field inferred from the S20RTSb seismic tomography model [Ritsema et al., 2004] and a constant velocity-density conversion factor of $0.15 \mathrm{~g} \mathrm{~cm}^{-3} \mathrm{~km}^{-1} \mathrm{~s}$. Because near-surface tomography may be partially determined by isostatically compensated compositional differences [e.g., Jordan, 1975], we do not impose density anomalies above $325 \mathrm{~km}$ in all models. This method for defining the mantle density heterogeneity has been used by others to predict mantle flow [e.g., Behn et al., 2004]. To quantify mantle shear tractions that this flow exerts on the lithosphere, we measure the horizontal shear stress on an imposed rigid surface boundary condition [e.g., 


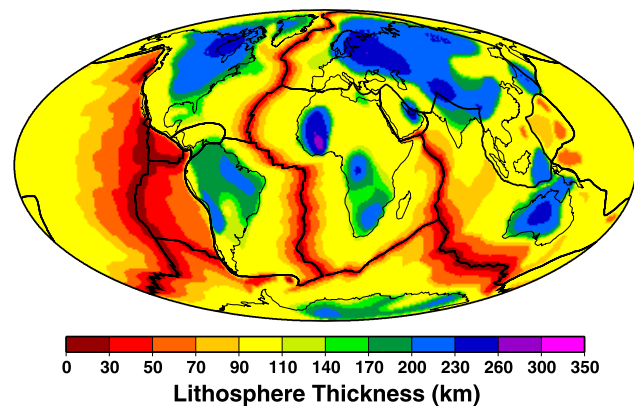

Figure 1. Estimated thickness of the lithosphere, determined using lithospheric age for oceanic areas and the thickness of positive seismic velocity anomalies for continental areas [Gung et al., 2003].

Lithgow-Bertelloni and Richards, 1995]. We compared these shear tractions for several different lithosphere and asthenosphere viscosity structures.

\subsection{Radial Viscosity Structure}

[5] We start by calculating tractions for a radial viscosity structure, against which we will compare tractions for more complicated, laterally-varying, viscosity structures. We use the same viscosity profile used by Behn et al. [2004], which includes lower mantle (below $670 \mathrm{~km})$ and lithospheric $(0$ $100 \mathrm{~km}$ ) layers that are 50 and 30 times more viscous than the upper mantle viscosity, which was taken to be $10^{21} \mathrm{~Pa} \mathrm{~s}$ (although the absolute value of viscosity is not relevant for ratios of tractions). Following Behn et al. [2004], we also include a low-viscosity asthenospheric layer that is 10 times less viscous than the upper mantle. We thus have set up the density and viscosity structures of this problem to reproduce the calculations that Behn et al. [2004] performed using a spectral code to predict shear in the asthenosphere. The computed strain rates reproduce the results of Behn et al. [2004], which confirms the accuracy of our finite element calculations for the layered viscosity case. Examining the shear tractions in this calculation (Figure 2a), we see that tractions generally are directed toward regions of downwelling (Tethyan subduction across southern Europe and Asia and circum-Pacific subduction) and away from regions of upwelling (dominated by Africa and the South Pacific). The largest tractions are those that surround the regions of convergence.

\subsection{Laterally-Varying Viscosity Structure}

[6] To isolate the influence of near-surface viscosity variations on shear tractions, we employ the same layered viscosity structure as above for the upper and lower mantles, but introduce changes only in the asthenospheric and lithospheric layers (above $300 \mathrm{~km}$ depth). Here, we introduce lateral viscosity variations expected from lithospheric complexity following the method of Conrad and Gurnis [2003]. We imposed an error-function temperature profile with a laterally-varying characteristic thickness (Figure 1) on the top $300 \mathrm{~km}$ of the finite element grid. For oceanic lithosphere, we defined this characteristic thickness as proportional to the square root of lithospheric age [Müller et al., 1997]. For the continents, we followed Gung et al. [2003], who used the maximum depth for which the velocity anomaly (from S20RTSb) is consistently greater than $+2 \%$ to estimate continental thickness at any given location. We imposed $100 \mathrm{~km}$ as the minimum continental and maximum oceanic thicknesses. By assigning temperature-dependent viscosity to these near-surface temperatures, we are able to introduce a smoothly-varying viscosity field that grades from stiff lithosphere near the cold surface to an imposed asthenospheric viscosity well below the characteristic lithosphere thickness. We follow Conrad and Gurnis [2003] in imposing temperature-dependent viscosity [e.g., Hirth and Kohlstedt, 1996], choosing a pre-exponential magnitude that produces an asthenosphere 10 times less viscous than that of the upper mantle (for direct comparison with the layered case), an activation energy of $200 \mathrm{~kJ} / \mathrm{mol}$ for the temperature-dependence, and a maximum viscosity 1000 times that of the upper mantle. The shear tractions produced by this "base case" calculation (Figure 2b) can be directly compared to the layered calculation (Figure 2a).

[7] The asthenosphere in these models is global in extent above $300 \mathrm{~km}$, but is significantly thinned beneath thick continental roots. We vary the pre-exponential viscosity magnitude to produce a range of asthenospheric viscosities that are $0.03,0.1$ (the "base case"), 0.3, and 1.0 times those of the upper mantle. For these cases, we must also vary the activation energy so that lithospheric viscosities remain similar between these models despite changes in the preexponential factor. We found that activation energies of $300,200,150$, and $100 \mathrm{~kJ} / \mathrm{mol}$ produce similar lithospheric viscosity profiles while allowing the asthenospheric viscosity to vary according to the above factors. The last of these reproduces the lithospheric viscosity profile used by

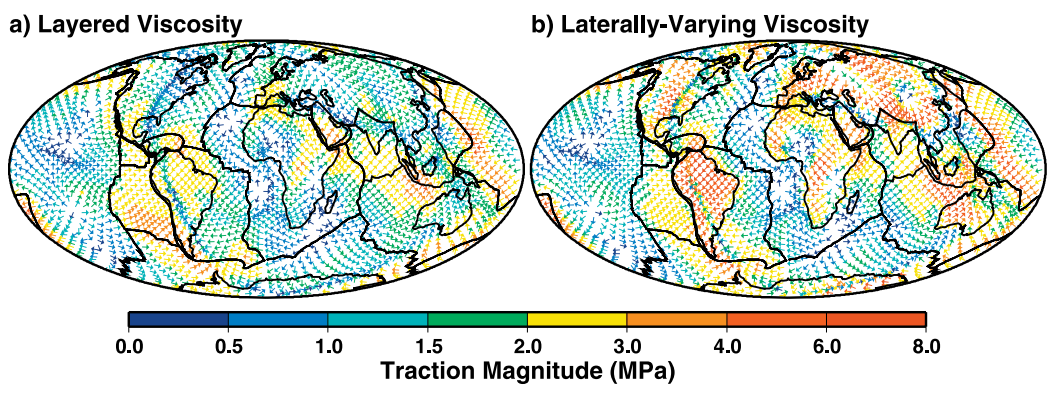

Figure 2. Shear tractions that mantle flow exerts on the lithosphere, as measured at the top of the finite element calculation, for (a) a layered viscosity structure and (b) a viscosity structure that includes lateral variations in viscosity associated with lithosphere thickness variations (Figure 1). Arrow directions and colors show shear traction azimuths and magnitudes, respectively. 
a) Difference in Traction Direction

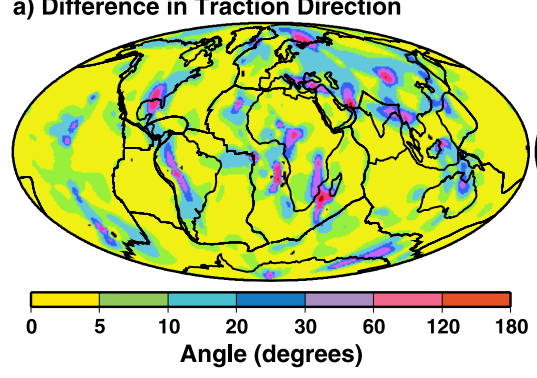

b) Ratio of Traction Magnitudes

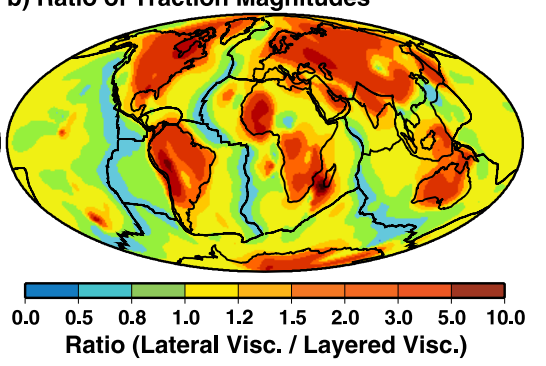

Ratio (Lateral Visc. / Layered Visc.)

Figure 3. A comparison between the shear tractions exerted on a lithosphere with a layered (Figure 2a) or laterallyvarying (Figure $2 b$ ) viscosity structure. Shown are (a) the difference in shear traction direction and (b) the factor by which shear traction magnitudes change when lateral variations in viscosity are introduced.

Conrad and Gurnis [2003], which does not include an asthenosphere.

\section{Lithospheric Thickness and Continental Roots}

[8] The shear tractions that the mantle exerts on a lithosphere with lateral viscosity variations (Figure $2 \mathrm{~b}$ ) are similar to those exerted on a layered lithosphere (Figure 2a). Because the basic pattern of basal shear tractions is controlled by the background mantle flow, lateral viscosity variations do not change the direction of shear tractions significantly, although we predict rotations of up to $20^{\circ}$ in azimuth (Figure 3a) near the edges of some cratons (such as eastern North America) where lateral viscosity variations are large.

[9] Lateral viscosity variations introduce more significant changes in the magnitude of shear tractions (Figure 3b), decreasing tractions near ridges where lithosphere thickness is small and increasing them by a factor of 2 to 5 for deeply penetrating cratons. When averaged globally, we see that the fractional change in traction magnitude increases monotonically with lithospheric thickness (red line, Figure 4). For the thinnest lithosphere near ridges, tractions are decreased by about a third due to the increased thickness of the asthenosphere. Ocean and continental areas with $100 \mathrm{~km}$ thick lithosphere (Figure 1) do not generally exhibit increased traction magnitude compared to the layered case (Figures $3 \mathrm{~b}$ and 4 ), which features a globally uniform $100 \mathrm{~km}$ thick lithosphere. Finally, we find that tractions are most effectively transmitted through a strong, deeply penetrating, continental root. In these regions, mantle tractions are 2 to 5 times larger (Figure $3 \mathrm{~b}$ ), and about three times larger on average (Figure 4), than they are for $100 \mathrm{~km}$ thick lithosphere. This is the case for cratons above both downwelling (compare Figures $2 \mathrm{a}$ and $2 \mathrm{~b}$ for North and South America, Australia, southeast Asia) and upwelling (southern Africa) flow. These results confirm and quantify Zhong's [2001] finding that deep continental roots increase the coupling between plates and mantle flow.

\section{Asthenospheric Viscosity}

[10] To determine how the viscosity of the asthenosphere affects mantle shear tractions, we varied the asthenospheric viscosity in the calculations with lateral viscosity variations using the method described above. Again, we find only small changes in the direction of mantle tractions compared to the layered case, but more significant changes in traction magnitudes (Figure 4). However, these changes in the magnitude of the tractions are proportionally much smaller than the changes in asthenospheric viscosity that cause them

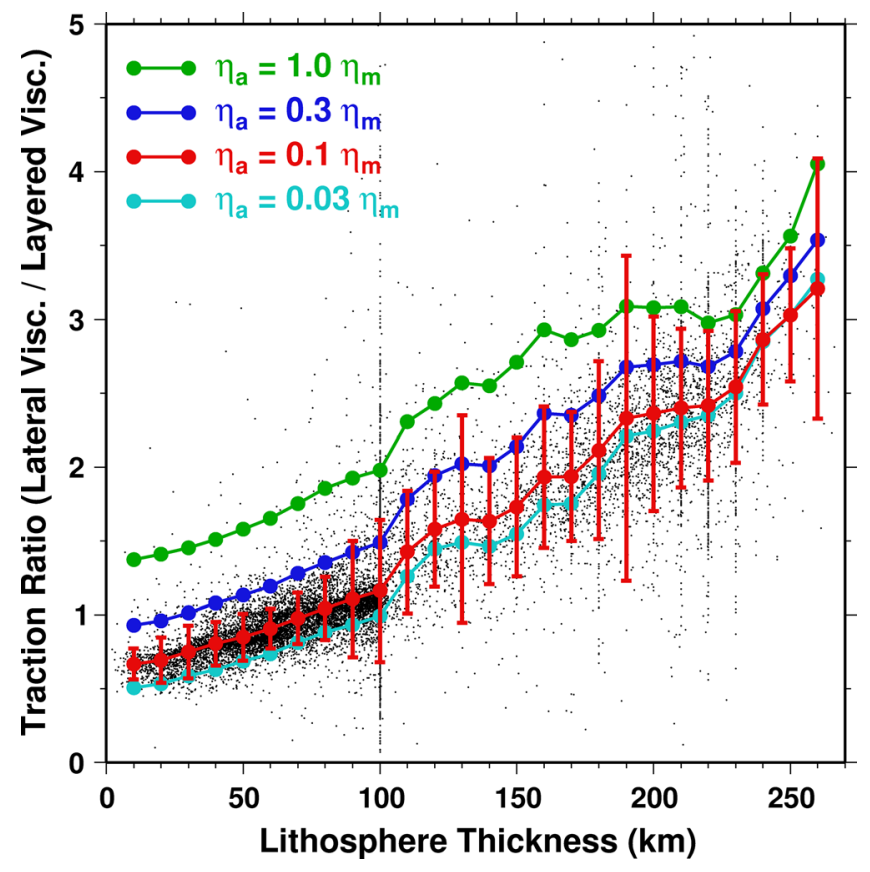

Figure 4. The ratio of traction magnitudes (Figure 3b), as a function of lithospheric thickness (Figure 1). Black dots show this ratio measured at each (approximately equallyspaced) point of the finite element grid for an asthenospheric viscosity 10 times less viscous than the upper mantle ("base case"). The average ratio of these points within $10 \mathrm{~km}$ depth bins is shown in red, with error bars denoting one standard deviation variation in this ratio. Other colors show the average ratio for traction magnitudes, calculated with lateral viscosity variations and an asthenospheric viscosity $\left(\eta_{\mathrm{a}}\right)$ of varying magnitude relative to upper mantle viscosity $\left(\eta_{\mathrm{m}}\right)$, compared to the layered viscosity calculation (with $\eta_{\mathrm{a}}=0.1 \eta_{\mathrm{m}}$ ). The plethora of points at $100 \mathrm{~km}$, and at $10 \mathrm{~km}$ steps for thicker lithosphere, arises from the assignment of thick oceanic or thin continental lithosphere to $100 \mathrm{~km}$ thickness (Figure 1), and to our parameterization of continental thickness using $10 \mathrm{~km}$ spacing. 
[Lithgow-Bertelloni and Richards, 1995]. Stress magnitudes are primarily controlled by the mantle density heterogeneity, which is unchanged. Decreasing the viscosity increases strain-rates in the asthenosphere, but only marginally diminishes the stress transmitted through it. Beneath continental roots, changes to the asthenosphere viscosity create almost no change in shear tractions (compare curves for large depths, Figure 4). This behavior is expected because the asthenosphere is thin in these regions. However, even for thick asthenosphere (thin lithosphere near ridges) shear tractions decrease by at most a factor of 3 when an asthenosphere 30 times less viscous than the underlying mantle is introduced (compare curves for small depths, Figure 4). For more moderate asthenospheric viscosity drops, the traction magnitude reduction is even smaller.

\section{Discussion and Conclusions}

[11] We have shown that the rheology of the lower lithosphere and asthenosphere exerts a primary control on the magnitude, but not the direction, of tractions that mantle flow exerts on the Earth's plates. However, we find that the thickness of the lithospheric layer, and the presence of continental roots in particular, is more important than the asthenospheric viscosity in determining the magnitude of these tractions. The presence of an asthenosphere does decrease shear tractions below lithosphere of all thicknesses, but the decrease is negligible if the asthenosphere is thinner than $100 \mathrm{~km}$ and is less than a factor of 2 if it is $200 \mathrm{~km}$ thick. Thus, even if continental roots are underlain by a thin asthenosphere [e.g., Gung et al., 2003], mantle tractions on their base may remain large compared to regions with thinner lithosphere. We find that the presence of an asthenosphere does not decouple the lithosphere from mantle flow [e.g., Forsyth and Uyeda, 1975], because mantle tractions are transmitted through this low-viscosity layer.

[12] The changes in shear tractions that are induced by lateral variations in lithospheric thickness will have important implications for predictions of plate-driving forces and the lithospheric stress field, studies of which have typically assumed a lithosphere with a uniform thickness. For example, the amplification of shear tractions beneath continental roots should propel thick continental lithosphere more strongly than neighboring lithosphere [e.g., Bokelmann, 2002], although we expect resisting tractions on the movement of deep continental roots through the mantle to be larger as well, potentially impeding their motion [e.g., Forsyth and Uyeda, 1975]. Because mantle shear stresses are amplified by increased continental thickness, their contribution to the lithospheric stress field will be increased relative to the stresses associated with crustal thickness variations [e.g., Lithgow-Bertelloni and Guynn, 2004]. The increased importance of mantle tractions in continental areas may help explain the enhanced deformation that continental lithosphere seems to have experienced compared to oceanic lithosphere.

[13] Acknowledgment. We thank the David and Lucille Packard Foundation and NSF grant EAR-0509882 for support, as well as Thorsten Becker and an anonymous reviewer for helpful comments.

\section{References}

Becker, T. W., and R. J. O'Connell (2001), Predicting plate motions with mantle circulation models, Geochem. Geophys. Geosyst., 2(12), doi:10.1029/2001GC000171.

Behn, M. A., C. P. Conrad, and P. Silver (2004), Detection of upper mantle flow associated with the African superplume, Earth Planet. Sci. Lett., 224, 259-274.

Bokelmann, G. H. R. (2002), Which forces drive North America?, Geology, 30, 1027-1030.

Cadek, O., and L. Fleitout (2003), Effect of lateral viscosity variations in the top $300 \mathrm{~km}$ on the geoid and dynamic topography, Geophys. J. Int., $152,566-580$.

Conrad, C. P., and M. Gurnis (2003), Mantle flow, seismic tomography and the breakup of Gondwanaland: Integrating mantle convection backwards in time, Geochem. Geophys. Geosyst., 4(3), 1031, doi:10.1029/ $2001 \mathrm{GC} 000299$.

Conrad, C. P., and C. Lithgow-Bertelloni (2002), How mantle slabs drive plate tectonics, Science, 298, 207-209.

Forsyth, D., and S. Uyeda (1975), On the relative importance of the driving forces of plate motion, Geophys. J. R. Astron. Soc., 43, 163-200.

Gung, Y., M. Panning, and B. Romanowicz (2003), Global anisotropy and the thickness of continents, Nature, 422, 707-711.

Hager, B. H. (1991), Mantle viscosity: A comparison of models from postglacial rebound and from the geoid, plate driving forces, and advected heat flux, in Glacial Isostasy, Sea-Level and Mantle Rheology, edited by R. Sabadini et al., pp. 493-513, Springer, New York.

Hager, B. H., and R. J. O'Connell (1981), A simple global model of plate dynamics and mantle convection, J. Geophys. Res., 86, 4843-4867.

Hirth, G., and D. L. Kohlstedt (1996), Water in the oceanic upper mantle: Implications for rheology, melt extraction and the evolution of the lithosphere, Earth Planet. Sci. Lett., 144, 93-108.

Jordan, T. H. (1975), The continental tectosphere, Rev. Geophys., 13, 1-12.

Lithgow-Bertelloni, C., and J. H. Guynn (2004), Origin of lithospheric stress field, J. Geophys. Res., 109, B01408, doi:10.1029/ 2003 JB002467.

Lithgow-Bertelloni, C., and M. A. Richards (1995), Cenozoic plate driving forces, Geophys. Res. Lett., 25, 1317-1320.

Müller, R. D., W. R. Roest, J.-Y. Royer, L. M. Gahagan, and J. G. Sclater (1997), Digital isochrons of the world's ocean floor, J. Geophys. Res., $102,3211-3214$.

Ritsema, J. H., J. van Heijst, and J. H. Woodhouse (2004), Global transition zone tomography, J. Geophys. Res., 109, B02302, doi:10.1029/ 2003JB002610.

Rudnick, R., W. McDonough, and R. O'Connell (1998), Thermal structure, thickness and composition of continental lithosphere, Chem. Geol., 145, $295-411$.

Steinberger, B., H. Schmeling, and G. Marquart (2001), Large-scale lithospheric stress field and topography induced by global mantle circulation, Earth Planet. Sci. Lett., 186, 75-91.

Stoddard, P. R., and D. Abbott (1996), Influence of the tectosphere upon plate motion, J. Geophys. Res., 101, 5425-5433.

Zhong, S. (2001), Role of ocean-continent contrast and continental keels on plate motion, net rotation of the lithosphere, and the geoid, J. Geophys. Res., 106, 703-712.

Zhong, S., M. T. Zuber, L. N. Moresi, and M. Gurnis (2000), The role of temperature-dependent viscosity and surface plates in spherical shell models of mantle convection, J. Geophys. Res., 105, 11,063-11,082.

C. P. Conrad, Department of Earth and Planetary Sciences, Johns Hopkins University, Baltimore, MD 21218, USA. (conrad@jhu.edu)

C. Lithgow-Bertelloni, Department of Geological Sciences, University of Michigan, Ann Arbor, MI 48109, USA. 